\title{
Tadpoles of the midwife toad Alytes obstetricans scavenging carrion
}

\author{
DAVID J. CLEMENS ${ }^{1 *}$, LLOYD ROSE ${ }^{1} \&$ STEVEN J. R. ALLAIN ${ }^{2}$ \\ ${ }^{1}$ Bedfordshire Reptile and Amphibian Group \\ ${ }^{2}$ Cambridgeshire \& Peterborough Amphibian and Reptile Group \\ *Corresponding author e-mail: lutonreptilerescue@hotmail.co.uk
}

$T^{\text {neis }}$ he common midwife toad (Alytes obstetricans) is not native to Great Britain but approximately thirty introduced populations are known (Allain \& Goodman, 2017; unpublished data), the most well-known of which is in Bedford (Beebee \& Griffiths, 2000). The tadpoles of $A$. obstetricans grow to $80 \mathrm{~mm}$ in length, or $90 \mathrm{~mm}$ in exceptional circumstances (Boulenger, 1896). This makes their tadpoles easily recognisable and conspicuous within a given body of water, as they dwarf those of any native anurans, especially given that $A$. obstetricans tadpoles may overwinter if laid too late in the season to metamorphose (Speybroeck et al., 2016).

The feeding biology of $A$. obstetricans tadpoles is not well known, which is the case for most species (Pryor, 2014). For the captive rearing of Alytes tadpoles, there is a tendency to assume that they are omnivorous, consequently they are offered fish flakes, trout pellets, grass pellets, tubifex worms and spirulina algae amongst others (Wells et al., 2015). While in a study of the effects of microplastics, the tadpoles were fed on a diet of periphyton, which can be found on most surfaces in aquatic ecosystems (Boyero et al., 2020). Following research into the digestive system of the species and through direct observation (Boulenger, 1896), it has been stated that the tadpoles of $A$. obstetricans are predators rather than scavengers.

At 12:03 h on 23 April 2021, approximately ten $A$. obstetricans tadpoles were observed feeding upon a recently

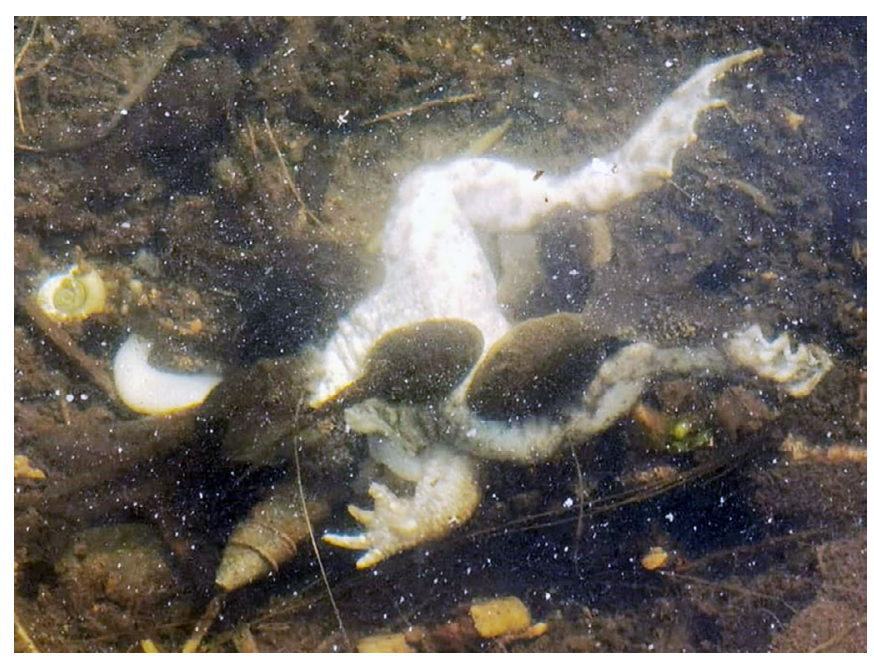

Figure 1. The tadpoles of the common midwife toad feeding on the carcass of the common frog deceased common frog Rana temporaria (Fig. 1; BHS video, 2021) at Hill Rise Nature Reserve, Bedford, Bedfordshire $\left(52^{\circ} 08^{\prime} 52^{\prime \prime} \mathrm{N}, 000^{\circ} 28^{\prime} 16^{\prime \prime} \mathrm{W}\right)$, and a second group of approximately ten tadpoles were observed in the same pond, approximately $4 \mathrm{~m}$ away feeding upon a drowned earthworm (BHS video, 2021). This feeding behaviour was observed for several minutes, and it is our belief that these observations may represent the first report of carrion scavenging behaviour in $A$. obstetricans.

Most husbandry guidelines for $A$. obstetricans tadpoles state that they are herbivorous (Boyero et al., 2020; Wells et al., 2015) but in light of this observation of carnivorous behaviour, it appears that the tadpoles of $A$. obstetricans are similar to other anurans (such as Rana temporaria), which become omnivorous at later Gosner stages.

\section{REFERENCES}

Allain, S.J.R. \& Goodman, M.J. (2017). Using call playbacks to investigate a population of non-native midwife toads Alytes obstetricans (Laurenti, 1768) in Cambridge, UK. Herpetological Bulletin 140: 28-30.

Beebee, T.J.C. \& Griffiths, R.A. (2000). Amphibians and Reptiles. A Natural History of the British Herpetofauna. London, HarperCollins. 270 pp.

BHS video. (2021). Tadpoles of the midwife toad Alytes obstetricans scavenging carrion. https://youtu. be/4tvaxPHEfHU

Boulenger, G.A. (1896). The Tailless Batrachians of Europe, Volume 1. London, Ray Society. $210 \mathrm{pp}$.

Boyero, L., López-Rojo, N., Bosch, J., Alonso, A., CorreaAraneda, F. \& Pérez, J. (2020). Microplastics impair amphibian survival, body condition and function. Chemosphere 244: 125500.

Pryor, G.S. (2014). Tadpole nutritional ecology and digestive physiology: implications for captive rearing of larval anurans. Zoo Biology 33: 502-507.

Speybroeck, J., Beukema, W., Bok, B. \& Van Der Voort, J. (2016). Field Guide to the Amphibians and Reptiles of Britain and Europe. London, Bloomsbury Publishing. 432 pp.

Wells, E., Garcia-Alonso, D., Rosa, G.M., Garcia, G. \& Tapley, B. (2015). Amphibian Taxon Advisory Group Best Practice Guidelines for Midwife toads (Alytes sp.). https://www. eaza.net/assets/Uploads/CCC/2015-Midwife-toadsEAZA-Best-Practice-Guidelines-Approved.doc.pdf. (Accessed 9th May 2021).

Accepted: 9 June 2021 